\title{
RESEARCH PAPER \\ Effect of the inoculum size on the axenic in vitro production of Steinernema carpocapsae
}

\author{
Juan Suárez-Sánchez ${ }^{1}$, Raquel Alatorre-Rosas², Héctor M. Poggi-Varaldo1, and \\ Josefina Barrera-Cortés ${ }^{1}$ \\ ${ }^{1}$ Departamento de Biotecnología y Bioingeniería, Centro de Investigación y de Estudios Avanzados \\ del Instituto Politécnico Nacional (CINVESTAV)-Instituto Politécnico Nacional (IPN), Av. Instituto \\ Politécnico Nacional 2508, San Pedro Zacatenco CP 07360, México DF, México. \\ ${ }^{2}$ Entomología y Acarología, Fitosanidad. Colegio de Postgraduados, Montecillo. Km 36.5 Carretera México \\ Texcoco. CP 56240, Edo. México.
}

\begin{abstract}
J. Suárez-Sánchez, R. Alatorre-Rosas, H.M. Poggi-Varaldo, and J. Barrera-Cortés. 2012. Effect of the inoculum size on the axenic in vitro production of Steinernema carpocapsae. Cien. Inv. Agr. 39(1): 137-145. The effect of inoculum size on the axenic in vitro production of Steinernema carpocapsae, using a transparent medium with hemoglobin and cholesterol, was studied. Axenic cultivation was performed with fertile eggs of $S$. carpocapsae (hatching of eggs: $89 \pm 4 \%$ ), which were obtained by lyses of female nematodes and subsequent incubation. Two important aspects of this work include the use of a completely transparent medium enriched with hemoglobin and cholesterol and the high multiplication factor of the population (MFIP) of 87 , which is considered high for in vitro axenic cultures of nematodes. In vivo methods have the advantage of high MFIP, but they also have the disadvantage of the high number and complexity of the operations involved for the purposes of harvesting axenic nematodes. It is assumed that the availability of a high number of nematodes in a transparent medium will further encourage the characterization of new native strains of nematodes.
\end{abstract}

Key words: Axenic culture, hemoglobin, in vitro culture; Steinernema carpocapsae, transparent medium.

\section{Introduction}

The use of entomopathogenic nematodes (EPN) for the control of agricultural pests in their larval stage has been considered an environmentally safe alternative to chemical insecticides (Ehlers, 1996). EPN usefulness lies in its toxic activity,

Received January 21, 2011. Accepted November 1, 2011. Corresponding author: jbarrera@cinvestav.mx as it targets specific insects within a wide range of genera. Steinernema and Heterorhabditis are genera that contain the highest number of EPN species and are characterized by living in bacterial symbiosis with Xenorhabdus spp. and Photorhabdus spp., respectively (Forst and Nealson, 1996).

Successful market penetration of nematode-based products requires efficient in vitro production on a large scale; however, processes with these 
characteristics can only be implemented if the biochemical and nutritional needs of EPN are available. The axenic culture (pure culture) of EPN has been proposed as a method for gaining a deeper insight into these parameters (Krusberg and Sandanelli, 1984; Stoll, 1959). At the present time, in vivo and in vitro axenization methods are known (Lunau et al., 1993; Kikuta et al., 2008), but the scarcity of information on the specific nutritional requirements of nematode species has delayed the characterization and study of newly discovered strains.

The life cycle of EPNs is divided into three major phases of development that culminate in a resistance stage known as infective juvenile (IJ); that is, free-living soil nematodes that can be in contact with more than one soil microorganism. According to Bonifassi (1999), in in vitro culture, the removal of those microorganisms (sanitization) allows for the increase of both EPN yield and the percentage of transformation of juveniles into IJ. Nematode sanitization is accomplished through repeated washing using either distilled water or solutions prepared with chemical compounds, such as hydrogen peroxide, glutaraldehyde, antibiotics (penicillin, streptomycin and ampicillin) or antiseptics (sodium hypochlorite or merthiolate; Woodring and Kaya, 1988; Lunau et al., 1993). Sanitization does not ensure that a culture will be completely free of contaminant microorganisms, which is performed through axenic propagation.

An axenic culture of EPN is obtained using nematode eggs isolated by hydrolysis of gravid females or hermaphrodites (Ehlers and Strauch, 1994; Heungens et al., 1996). Nematode eggs produced using this method are called axenic eggs. Some specific applications of axenic cultures include the following: (i) inocula standardization in in vitro or large scale production processes (Lunau et al., 1993); (ii) studying substrate effects on nematode transformation and reproduction processes (Wrigth and Perry, 2002); (iii) elucidation of nematode-bacterium interactions among
Xenorhabdus and Steinernema found in nature (Sicard et al., 2005); and (iv) elimination of sex differentiation interference in nematode identification and characterization by molecular methods.

Because of the wide range of applications for axenic cultures, an improved in vitro axenic production of $S$. carpocapsae in liquid culture is presented here. Major features of our method are the complete in vitro characteristics and the use of a clean and transparent culture based on a highly soluble protein medium enriched with hemoglobin and cholesterol, which, in addition to the observation of the complete life cycle of S. carpocapsae, allows the precise assessment of reproductive capacity, growth and development timing of nematodes in a liquid culture.

\section{Materials and methods}

\section{Biological specimens}

Infective juveniles (IJ) of $S$. carpocapsae and its bacterial symbiont Xenorhabdus nematophila (X. nematophila) were donated by Raquel Alatorre Rosas from the Colegio de Postgraduados, Mexico. IJ were propagated in the last instar of Galleria mellonella for 7 days (Woodring and Kaya, 1988). The resulting IJ were kept at $3{ }^{\circ} \mathrm{C}$ in sterile water containing Triton X-100 at $0.01 \%$ $(\mathrm{v} / \mathrm{v})$. X. nematophila was isolated from a drop of the insect hemolymph, which was streaked by extension on nutrient agar plates with colorants added (NBTA medium; Akhurst, 1980) and incubated at $27^{\circ} \mathrm{C}$. The resulting $X$. nematophila Phase I was preserved in glycerol solution $(25 \%$ v/v) at $-80^{\circ} \mathrm{C}$.

\section{Production of S. carpocapsae adult stages}

Aliquots of $1 \mathrm{~mL}$ of $X$. nematophila phase I $\left(10^{9}\right.$ cell $\mathrm{mL}^{-1}$ ), previously propagated on a basal medium for nematode production (BAM medium: tripticasein soy broth, $4 \%(\mathrm{w} / \mathrm{v})$; yeast extract, $3 \%$ 
$(\mathrm{w} / \mathrm{v}))$ for $48 \mathrm{~h}$ at $28^{\circ} \mathrm{C}$ and $120 \mathrm{rpm}$, were spread onto nutrient agar with pig fat added (NAG agar: $2.3 \%(\mathrm{w} / \mathrm{v})$ nutrient agar and $0.26 \%(\mathrm{w} / \mathrm{v})$ pig fat) and contained in $8.5-\mathrm{cm}$ diameter Petri dishes. The plates were incubated in the dark at $28{ }^{\circ} \mathrm{C}$ until a homogeneous and dense lawn of $X$. nematophila was observed (approximately 24 h) Woust (1981). Petri dishes were inoculated with IJ, previously sanitized with merthiolate solution $(0.2 \% \mathrm{w} / \mathrm{v})$. The first generation of adult-stage nematodes was recovered through repeated washing (three times) of the resulting nematodes with sterile distilled water. The adequate number of IJ to be inoculated on the $X$. nematophila lawn was determined by IJ dosification at initial concentrations of $100,500,1000,1500$ or 3000 IJ's per plate $(\mathrm{CV} \leq 12 \%)$, which corresponded to treatments A, B, C, D, and E, respectively. Viable counting, sex differentiation, and length measurement of nematodes were determined for each test.

\section{First-generation axenic juveniles $J 1$}

The first generation of adult $S$. carpocapsae produced from the monoxenic culture was deposited in 50-mL sterile conical tubes for egg release with $0.25 \mathrm{~mL}$ of a solution for nematode digestion (LYSOL: $\mathrm{NaOH}, 1.6 \%$ (v/v); Cloralex bleach ${ }^{\mathrm{TM}}$ $8 \%(\mathrm{v} / \mathrm{v})$, Alen Mexico: active compound $\mathrm{NaClO}$ at $5.25-5.5 \%(\mathrm{v} / \mathrm{v}))$ per 100 adult nematodes. The tubes were placed into an orbital shaker at 100 rpm for $10 \mathrm{~min}$, and the eggs were separated by two washes with $0.3 \mathrm{~mL}$ of phosphate solution (PBS: $\mathrm{KH}_{2} \mathrm{PO}, 0.6 \%(\mathrm{w} / \mathrm{v}) ; \mathrm{Na}_{2} \mathrm{HPO}_{4}, 1.2 \%(\mathrm{w} / \mathrm{v})$; $\left.\mathrm{MgSO}_{4} \cdot 7 \mathrm{H}_{2} \mathrm{O}, 0.05 \%(\mathrm{w} / \mathrm{v}) ; \mathrm{NaCl}, 1.0 \%(\mathrm{w} / \mathrm{v})\right)$. Washing involved agitation (vortex), centrifugation (5000 rpm for $3 \mathrm{~min}$ ) and supernatant decanting.

Isolated eggs were resuspended in $10 \mathrm{~mL}$ of a sanitizing solution (PHYSA solution: $\mathrm{NaCl}, 0.85 \%$ (w/v); ampicillin, $0.1 \%$ (w/v); streptomycin, $0.1 \%$ $(\mathrm{w} / \mathrm{v}))$. The eggs were then placed in Petri dishes for static incubation at $28{ }^{\circ} \mathrm{C}$. PHYSA solution samples were used for the analysis of egg and juvenile J1 counts. The purity of isolated eggs was verified using $200 \mu \mathrm{L}$ aliquots incubated in
$0.8 \%(\mathrm{w} / \mathrm{v})$ nutritive broth (NB) and yeast extract/ salt (YS) culture media (Dye, 1968) at $30^{\circ} \mathrm{C}$ and 120 rpm over 25 days.

\section{Axenic liquid culture of S. carpocapsae}

Cylindrical bottles (5.5 $\mathrm{cm}$ in diameter) containing 10 $\mathrm{mL}$ of basal medium supplemented with hemoglobin at 1\% (Lunau et al., 1993) and Tween 80 at $0.4 \%$ (w/v) (BAMHIN) were inoculated with $1 \mathrm{~mL}$ of axenic J1 $\left(1000 \mathrm{~J} 1 \mathrm{~mL}^{-1}\right)$ and further incubated at $25^{\circ} \mathrm{C}$ at 100 rpm in an orbital shaker. Viable counting, sex differentiation, and length measurement of nematodes were analyzed. Analysis was performed using culture samples diluted in the range of $10^{-1}-10^{-3}$.

\section{Analyses}

Viable counting of nematodes was determined under microscopic observations (Olympus CH30 microscope) of diluted culture samples using a McMaster chamber.

Biomass was determined by dry weight from 5 -mL culture aliquots filtered through $0.45-\mu \mathrm{m}$ nitrocellulose membranes, previously set at a constant weight by drying at $80^{\circ} \mathrm{C}$ and vacuum pressure. Biomass quantification of nematodes of the first and second generations was performed by previously separating the nematodes using $50-\mu \mathrm{m}$ polyester membranes.

Differential accounting of developmental stages was determined by microscopic observation based on the characteristic morphology of culture age and the apparent length of nematode stages. Analysis was performed with culture samples cooled to $3{ }^{\circ} \mathrm{C}$ for $30 \mathrm{~min}$. Developmental stages were registered using a digital camera coupled to an Olympus CH30 microscope.

The nematode length was determined using quantitative image analysis. The length reported is the average of 20 nematodes. 


\section{Results and discussion}

Axenic eggs produced from IJ monoxenic cultures

Symbiont $X$. nematophila cells grown on NAG medium favored a high recovery $(100 \%)$ of nematode IJ. The latter showed a rapid transformation to juvenile J4 stage (after $24 \mathrm{~h}$ ) and young adults (Y) after $48 \mathrm{~h}$. The reproductive maturity of female nematodes was observed at $72 \mathrm{~h}$. Transformation percentage of IJ in first-generation females was $51 \pm 9 \%$, with a length of $4,932 \pm 308 \mu \mathrm{m}$; male nematode length was $1,814 \pm 81 \mu \mathrm{m}$. These measurements are consistent with those reported by Shishiniova et al. (1998).

The effect of inoculum size on fecundity and fertility of female nematodes is shown in Table 1. The female nematode fecundity and fertility remain similar for tests A and B (100 and $500 \mathrm{IJ}$, respectively), even when the $X$. nematophila dose was reduced fivefold. Concerning treatments $C$, $\mathrm{D}$ and $\mathrm{E}$, where IJ inoculums were added at concentrations of 1000, 1500 and 3000, respectively, fecundity and fertility fell in the range $21-40 \%$. Even when nematode production decreased by more than $1000 \mathrm{IJ}$, an inoculum size of $3000 \mathrm{IJ}$ is recommended because for each 3000 initial IJ, 432000 IJ are produced; only 19300 IJ were produced from the test with $100 \mathrm{IJ}$ added.

Published methodologies about axenic cultures of EPN differ from each other, primarily in the culture media composition (natural or artificial) but also in the chemical compounds used for nematode tissue lyses. Lunau et al. (1993) grew one mature female in nutrient agar plates supplemented with rat liver and reported a fecundity of $1,024 \pm 682$ after 3 days of nematode cultivation. Han and Ehlers (2000) counted $528 \pm 656$ nematodes per IJ hosted by Galleria mellonella over three weeks. When testing EPN in cultured insect cells under axenic conditions, Kikuta et al. (2008) obtained 47 nematodes per $S$. carpocapse axenic egg inoculated in microplates containing Spodoptera frugiperda cells (Sf9 cells) as culture medium. Although the results were promising, the complexity of the experimental manipulations in in vivo procedures or for the pretreatment when organic substrates are involved (rat liver) increases complexity and production cost. The substrates used in our work allowed a simpler and more affordable procedure, as well as non-degradability of substances when the medium was sterilized with moist heat. Furthermore, axenic eggs remained free of bacterial or fungal contaminants during the 25-day trial when they were incubated in NB and YS media (purity controls in section 'Firstgeneration axenic juveniles J1').

Both the use of a previously sanitized inoculum with the capacity to be transformed into adults in an in vitro culture and the use of LYSOL for adult digestion, as proposed in this work, facilitated axenic nematode production with two principal advantages: first, the simplification of the axenic egg

Table 1. Transformation of IJ-stage $S$. carpocapsae to first-generation female adults; female nematode fecundity and fertility. IJ monoxenic cultures on NAG medium at $28^{\circ} \mathrm{C}$.

\begin{tabular}{lcccc}
\hline $\begin{array}{l}\text { Treatment } \\
\text { (IJ per plate) }\end{array}$ & $\begin{array}{c}\text { Female nematodes } \\
\text { per plate at } 72 \mathrm{~h} \mathrm{( \% )}\end{array}$ & $\begin{array}{c}\text { Fecundity } \\
\left(\text { eggs female }^{-1}\right)\end{array}$ & $\begin{array}{c}\text { Hatched eggs } \\
\text { per female }\end{array}$ & $\begin{array}{c}\text { Fertility (\%) } \\
\text { (eggs hatched in juveniles J1) }\end{array}$ \\
\hline A (100) & $47 \pm 12$ & $193 \pm 64$ & $170 \pm 56$ & $88 \pm 4$ \\
B (500) & $46 \pm 20$ & $187 \pm 10$ & $165 \pm 9$ & $88 \pm 2$ \\
C (1000) & $51 \pm 9$ & $140 \pm 21$ & $130 \pm 20$ & $93 \pm 2$ \\
D (1500) & $51 \pm 7$ & $120 \pm 22$ & $102 \pm 20$ & $85 \pm 5$ \\
E (3000) & $52 \pm 9$ & $144 \pm 18$ & $134 \pm 19$ & $93 \pm 1$ \\
\hline
\end{tabular}


recuperation process to a simple washing process in triplicate; and second, the higher percentage of eggs hatching to juveniles J1 (Table 1).

\section{S. carpocapsae growth in axenic liquid culture}

Axenic $S$. carpocapsae growth on liquid medium lasted 25 days during which the lag, exponential, and stationary phases of its life cycle were well identified (Figure 1).

During the lag phase, which lasted 5 days, juveniles one (J1) were transformed approximately

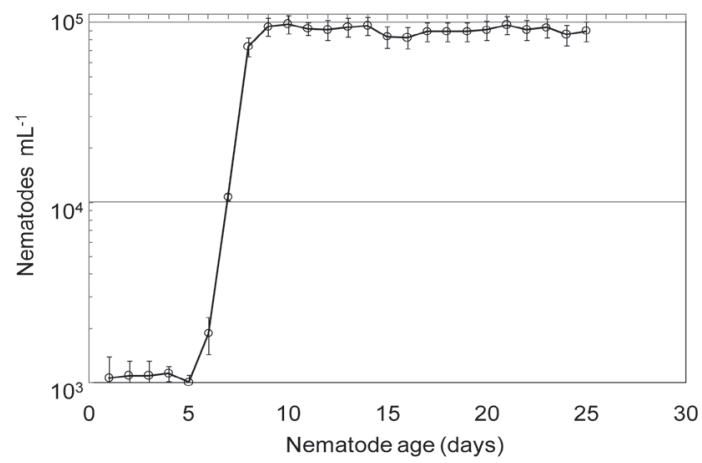

Figure 1. Growth kinetics of axenic $S$. carpocapsae in BHAMIN liquid media at $25^{\circ} \mathrm{C}$ and $100 \mathrm{rpm}$. every $24 \mathrm{~h}$, into juveniles $\mathrm{J} 2$, J3 and $\mathrm{J} 4$ of $96 \pm 17 \%$, $91 \pm 10 \%$ and $83 \pm 8 \%$, respectively (Table 2 ). Young adults were observed on the 5th day, but their reproduction began on the 6th day, when the nematode population was composed of $36 \pm 5 \%$ of females and $47 \pm 2 \%$ males. Because of the low decrease of the above juvenile transformation percentages $(<9 \%)$, a synchronic culture was assumed, which was corroborated in Figure 1 by rapid growth in the exponential stage, that was registered as a straight segment with high slope due to the log axis in Figure 1. According to Patel and McFadden (1978), a synchronous culture favors the multiplication factor of the initial nematode population (MFIP $=\mathrm{N}_{\max } / \mathrm{N}_{0} ; \mathrm{N}_{\max }$, number of nematodes at the end of the axenic liquid production; $\mathrm{N}_{0}$, number of nematodes at the beginning of the axenic liquid production). In this test, the MFIP was 87.

Nematode culture synchronization has been obtained through the inocula standardization on the size and density of eggs (Patel and McFadden, 1978). In our work, culture synchronization was ascribed to hatching of axenic eggs in a low-concentration $(0.85 \%)$ saline solution free of nutrients (PHYSA solution). This prevailing state

Table 2. Percentages of $S$. carpocapsae transformation in axenic liquid culture at $25^{\circ} \mathrm{C}$ and $100 \mathrm{rpm}$ using BAMHIN medium and an inoculum size of 1000 IJ.

\begin{tabular}{|c|c|c|c|c|c|c|c|c|c|c|c|}
\hline & & \multicolumn{10}{|c|}{ Culture Age (h) } \\
\hline & & 24 & 48 & 72 & 96 & 120 & 144 & 240 & 360 & 480 & 600 \\
\hline \multirow{7}{*}{ 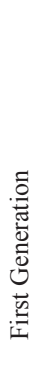 } & $\mathrm{J} 1$ & $4 \pm 2$ & $2 \pm 1$ & 0 & 0 & 0 & 0 & 0 & 0 & 0 & 0 \\
\hline & $\mathrm{J} 2$ & $96 \pm 17$ & $7 \pm 2$ & $3 \pm 1$ & $2 \pm 1$ & 0 & 0 & 0 & 0 & 0 & 0 \\
\hline & $\mathrm{J} 3$ & 0 & $91 \pm 10$ & $14 \pm 4$ & $3 \pm 1$ & $3 \pm 1$ & 0 & 0 & 0 & 0 & 0 \\
\hline & $\mathrm{J} 4$ & 0 & 0 & $83 \pm 8$ & $35 \pm 3$ & $23 \pm 7$ & $17 \pm 1$ & $1 \pm 1$ & 0 & 0 & 0 \\
\hline & Female & 0 & 0 & 0 & $\begin{array}{r}27 \\
\pm 6\end{array}$ & $35 \pm 3$ & $36 \pm 5$ & $47 \pm 0$ & $40 \pm 1$ & $17 \pm 1$ & $2 \pm 0$ \\
\hline & Male & 0 & 0 & 0 & $33 \pm 7$ & $39 \pm 8$ & $47 \pm 2$ & $50 \pm 1$ & $43 \pm 1$ & $18 \pm 1$ & $2 \pm 0$ \\
\hline & $\mathrm{IJ}$ & 0 & 0 & 0 & 0 & 0 & & & & & \\
\hline 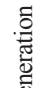 & $\begin{array}{l}\text { Eggs and } \\
\text { juveniles }\end{array}$ & 0 & 0 & 0 & 0 & 0 & $48 \pm 19$ & $95 \pm 5$ & $95 \pm 5$ & $94 \pm 6$ & $91 \pm 9$ \\
\hline $\begin{array}{l}\text { हू } \\
\text { हू }\end{array}$ & $\mathrm{IJ}$ & 0 & 0 & 0 & 0 & 0 & $2 \pm 1$ & $2 \pm 0$ & $17 \pm 1$ & $26 \pm 9$ & $35 \pm 2$ \\
\hline
\end{tabular}


of starvation prevented the development of juveniles $\mathrm{J} 1$ to juveniles $\mathrm{J} 2$ and consequently, allowed for the production of an inoculum of nematodes in a predominant single stage of development.

Figure 2 shows the nematode stage evolution when nematodes were immersed in the transparent BAMHIN medium. In culture media, where hemoglobin is one of the components, hemoglobin aggregates are commonly formed, producing some interference with the analysis of nematode morphology as well as biomass quantification by dry weight. Such interferences were eliminated by the solubilization of the hemoglobin with Tween 80 added at $4 \%$ to the culture medium. It is important to state that the transparency of the BAMHIN medium allowed some morphological details of nematode life cycle to be appreciated, as shown in Figure 2.
The exponential growth phase began at day 6 and lasted for 4 days, during which the mating and ovipositation processes were clearly observed (Figure 2). The reproduction process gave rise to a culture where first-generation adult nematodes and second-generation juvenile nematodes coexisted. A maximum nematode concentration $\left(\mathrm{N}_{\max }\right)$ occurred at day 10 with $87,000 \pm 2,200$ nematodes $\mathrm{mL}^{-1}$, where $99 \pm 5 \%$ were secondgeneration juveniles (Table 2).

The MFIP of first-generation axenic nematodes was $87\left(\mathrm{~N}_{0}=1000\right.$ nematodes $\left.\mathrm{mL}^{-1}\right)$ at day 10, which was considered among the highest MFIP reported in the literature for this type of procedure. Lunau et al. (1993) reported an MFIP of 65 for axenic cultures of $S$. carpocapsae in a liquid substrate. Kikuta et al. (2008), who reproduced $S$. carpocapsae on the Sf9 cell line, determined

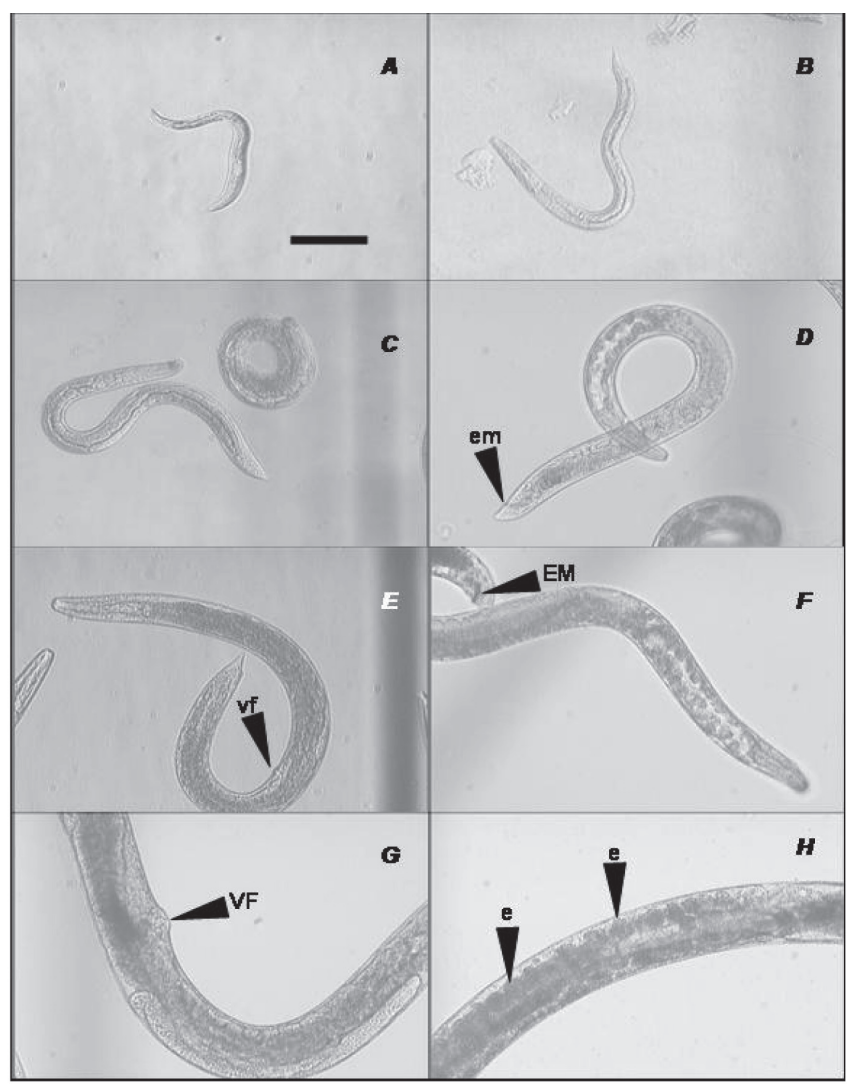

Figure 2. Morphological characteristics of $S$. carpocapsae stages of growth in axenic BHAMIN liquid media at $25^{\circ} \mathrm{C}$ and $100 \mathrm{rpm}$. A: J2 juvenile stage, 24 h; B: J3 juvenile stage, 36 h; C: J4 juvenile stage, 72 h; D and E: young adults, 96 h (VF: incipient development of the vulva; em: male spicules). F and G: mature adults, $120 \mathrm{~h}$ (EM: male spicules; VF: hypertrophied vulva of a mature female; H: uterus of a gravid female with embryos; e: embryos). Scale bar: $150 \mu \mathrm{m}$. 
an MFIP of 45 at day $10\left(\mathrm{~N}_{0}=50\right.$ juveniles $\mathrm{J} 1$ and $\mathrm{N}_{\text {max }}=7,500$ nematodes $\mathrm{mL}^{-1}$ ); however, this value dropped to 25 by day 30 . This latter MFIP value was probably due to a poor diet due to insect cell degradation. Such problems did not occur in our in vitro cultures, where the cultures remained stable with no apparent degradation after the population reached its maximum.

The stationary phase began on day 11 , with a juvenile concentration of $91 \pm 9 \%$ that remained stable until day 25 , when nematode cultivation was finished. Transformation of juveniles to second-generation IJ was detected at day 15 . This transformation was gradual and its low efficiency of IJ production was low to moderate, 35 $\pm 2 \%\left(\mathrm{~N}_{\mathrm{IJ}}=28,900 \pm 1,900 \mathrm{IJ} \mathrm{mL}^{-1}\right)$, as observed in Table 2. The second nematode generation was not significantly transformed and retained characteristics that corresponded to the $\mathrm{J} 3$ stage.

\section{Length and biomass of S. carpocapsae}

Figure 3 shows the evolution of length and biomass of $S$. carpocapsae at different stages of development: juveniles J2, J3, J4, young adults (Y) and adults (Ad). The length $\lambda_{\mathrm{f}}$ and $\lambda_{\mathrm{m}}$ for female and male nematodes was $3,487 \pm 420$ and 1,502 \pm $264 \mu \mathrm{m}$, respectively. Nematode lengths were calculated by measuring the length of nematodes at the end of the lag phase and at the beginning of the stationary phase. Male length was consistent with results reported by Shishiniova et al. (1998), who worked with in vivo cultures of $S$. carpocapsae. Female length in our work was, in fact, shorter than those observed by Shishiniova et al. (1998), which could be due to the absence of the symbiotic bacteria in our work, whose cells have been considered an essential nutritional factor for optimal development of $S$. carpocapsae in a monoxenic liquid culture (Friedman, 1990).

Total biomass and male nematode length of $S$. carpocapsae results adequately fit the sigmoidal model of Chapman-Richards of three parameters

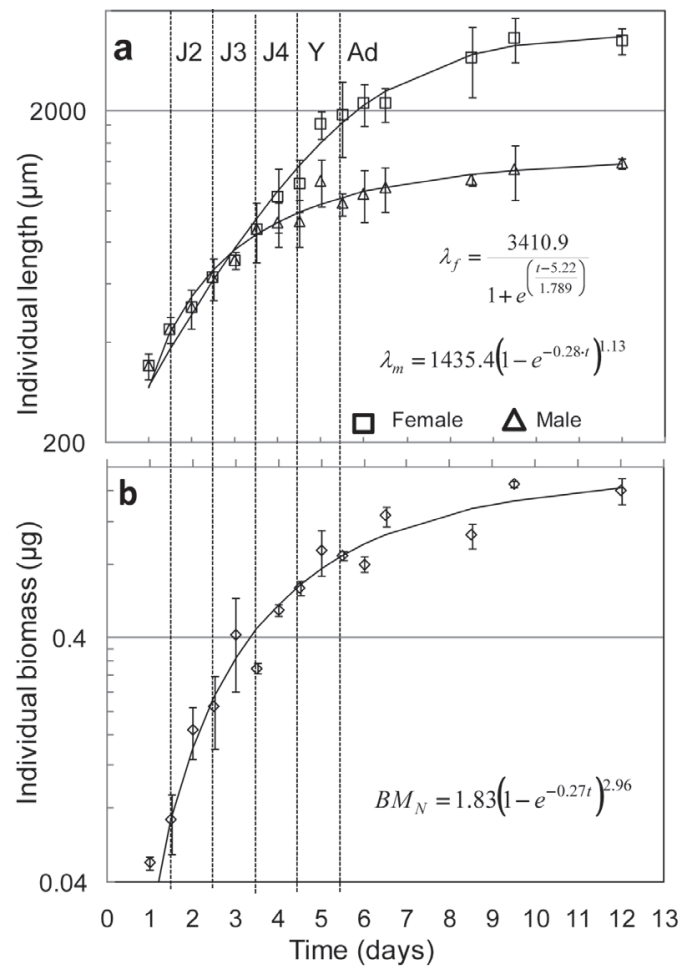

Figure 3. (a) Length of axenic $S$. carpocapsae cultivated in BAMHIN medium at $25^{\circ} \mathrm{C}$ and $100 \mathrm{rpm}$ during $0-12 \mathrm{~d}$, female ( $\square$ ) and male $(\Delta)$. (b) nematode biomass $(\diamond)$ as dry weight during $0-12 \mathrm{~d}$ (male and female nematodes were not differentiated). $\mathrm{J} 2=\mathrm{J} 2$ juvenile stage, $\mathrm{J} 3=\mathrm{J} 3$ juvenile stage, $\mathrm{J} 4=\mathrm{J} 4$ juvenile stage or preadult, $\mathrm{Y}=$ young adults and Ad=mature adults, $\lambda_{\mathrm{f}}=$ female nematode length, $\lambda_{\mathrm{m}}=$ male nematode length, $B M_{N}=$ biomass of nematodes.

(Sigma plot V7.0, Systat Software Inc.), which coincided with the observations made by Schiemer (1982) when studying Caenorhabditis briggsae. Female nematode length of $S$. carpocapsae was better adjusted to a simple sigmoid 3 parameter model. For all fittings, the correlation coefficients were $>0.96$.

In conclusion, it was found that the use of LYSOL for nematode lysis and the subsequent egg incubation in PHYSA is an attractive and inexpensive procedure for isolating large quantities of fertile $S$. carpocapsae eggs without affecting the life cycle of nematodes. An MFIP of 87 is among the highest values reported in the literature for in vitro procedures. In addition to the high MFIP, the transparent culture medium played an important role because it 
made the microscopic observations of nematode life cycle clearer; consequently, the precision of biomass analysis could be improved. It is well known that in vivo methods have the advantage of high yield; however, in vitro methods also offer the advantage of reducing the number and complexity of operations involved in in vivo methods.

\section{Acknowledgments}

The authors wish to thank to Centro de Investigación y de Estudios Avanzados del Instituto Politécnico Nacional (CINVESTAV)-Instituto Politécnico Nacional (IPN) for supporting this project.

\section{Resumen}

J. Suárez-Sánchez, R. Alatorre-Rosas, H.M. Poggi-Varaldo y J. Barrera-Cortés. 2012. Efecto del tamaño de inóculo en la producción axénica in vitro de Steinernema carpocapasae. Cien. Inv. Agr. 39(1): 137-145. Se estudió el efecto del tamaño de inoculo en la producción axénica in vitro de Steinernema carpocapsae, utilizando un medio de cultivo transparente enriquecido con hemoglobina y colesterol. El cultivo axénico se llevó a cabo con huevos fértiles de $S$. carpocapsae (incubación de los huevos: $89 \pm 3 \%$ ) obtenidos por lisis de nematodos hembras y su subsecuente incubación en medio de cultivo adicionado con antibióticos. Dos aspectos importantes a destacar son el uso de un medio de cultivo totalmente transparente enriquecido con la hemoglobina y colesterol, y el alto factor de multiplicación de la población (MFIP) de 87, que se considera alto para cultivos axénicos in vitro. Los métodos in vivo tienen la ventaja de su alta MFIP, pero también tienen la desventaja del elevado número y complejidad de las operaciones involucradas en el proceso de cosecha de nematodos. Se considera que la disponibilidad de un alto número de nematodos en un medio de cultivo transparente favorecerá la caracterización de cepas nativas nuevas de nematodos.

Palabras clave: Cultivo axenico, cultivo in vitro, hemoglobina, medio de cultivo transparente, Steinernema carpocapsae.

\section{References}

Akhurst, R.J. 1980. Morphological and functional dimorphism in Xenorhabdus spp., bacteria symbiotically associated with the insect pathogenic nematodes Neoaplectana and Heterorhabditis. J. Gen. Microbiol. 121: 303-309.

Bonifassi, E., M. Fischer-Le Saux, N. Boemare, A. Lanois, C. Laumond, and G. Smart. 1999. Gnotobiological Study of infective juveniles and symbionts of Steinernema scapterisci: A model to clarify the concept of the natural occurrence of monoxenic associations in entomopathogenic nematodes. J. Invertebr. Pathol. 74(2): 164-172.
Dye, D.W. 1968. A taxonomic study of the genus Erwinia. I. The 'amylovora' group. New Zealand Journal of Science 11: 590-607.

Ehlers, R.U. 1996, Current and Future Use of Nematodes in Biocontrol: Practice and Commercial Aspects with Regard to Regulatory Policy Issues, Biocontrol. Sci. Techn. 6: 303-316.

Ehlers, R.U., and O. Strauch. 1994. Establishment of axenic and monoxenic cultures summary of a practical workshop session. In: Burnell. A.M., Ehlers, R.U., and Masson, J. P. (eds.). Genetics of entomopathogenic nematode-bacterium complex. European commission directorate-general XII, science, research and development environment research program, Luxemburg, 204 pp. 
Forst, S., and K. Nealson. 1996. Molecular biology of the symbiotic-pathogenic bacteria Xenorhabdus spp. and Photorhabdus spp. Microbiological Reviews 60(1): 21-43.

Friedman, M.J. 1990. Commercial production and development. In: R. Gaugler, and H.K. Kaya (eds.). Entomopathogenic nematodes in biological control. CRC Press, Boca Raton, Florida. 139 pp.

Han, R., and R.U. Ehlers. 2000. Pathogenicity, development and reproduction of Heterorhabditis bacteriophora and Steinernema carpocapsae under axenic in vivo conditions. J. Invertebr. Pathol. 75: 55-58.

Heungens, K., D. Mugniéry, M. Van Montagu, G. Gheysen, and A. Niebel. 1996. A method to obtain disinfected Globodera infective juveniles directly from cyst. Fundam. Appl. Nematol. 19: 91-93.

Kikuta, S., T. Kiuchi, F. Aoki, and N. Masao. 2008. Development of an entomopathogenic nematode, Steinernema carpocapsae, in cultured insect cells under axenic conditions. Nematology 10: 845-851.

Krusberg, L.R., and S. Sardanelli. 1984. Technique for axenizing nematodes. J. Nematol. 16(3): 348.

Lunau, S., S. Stoessel, A.J. Schmidt-Peisker, R.U. Ehlers. 1993. Establishment on monoxenic inocula for scaling up in vitro cultures of the entomopathogenic nematodes Steinernema spp. and Heterorhabditis spp. Nematologica 39: 385-399.

Patel, T.R., and B.A. McFadden. 1978. Axenic and synchronous cultures of Caenorhabditis elegans. Nematologica 24: 51-62.
Schiemer, F. 1982. Food dependence and energetic of free living nematodes. I. Respiration, growth and reproduction of Caenorhanditis briggsae (nematoda) at different levels of food supply. Oecologia 54: 108-121.

Shishiniova, M., L. Budurova, and D. Gradirarov. 1998. Steinernema carpocapsae (Weiser, 1955) (Nematoda: Rhabditida) - new species for entomopathogenic fauna of Bulgaria. Experimental Pathology and Parasitology, Bulgarian Academy of Sciences 1: 30-35.

Sicard, T.J., N.E. Boemare, O. Thaler, and C. Moulia. 2005. Effect of phenotypic variation Xenorhabdus nematophila on its mutualistic relationship with the entomopathogenic nematode Steinernema carpocapsae. Parasitology 131: 687-694.

Stoll, N.R. 1959. Conditions favoring the axenic culture of Neaoplectana glaseri, a nematode parasite of certain insect grubs. Ann. N.Y. Acad. Sci. 77 special issue (Axenic Culture of Invertebrate Metazoa: A Goal):126-136.

Wright, D.J., and R.N. Perry. 2002. Physiology and Biochemistry. In: Gaugler. R. (ed.). Entomopathogenic Nematology. CAB International Wallinford, UK. 145 pp.

Woodring, J.L., and H.K. Kaya. 1988. Steinernematid and Heterorhabditid Nematodes: A Handbook of Biology and Techniques, South. Coop. Ser. Bull. 331, Arkansas Agric. Exp. Stat.

Woust, W.M. 1981. Mass Production of the Entomogenous Nematode Heterorhabditis heliothidis (Nematoda: Heterorhabditidae) on Artificial Media. J. Nematol. 13: 467-469. 
